\title{
Editorial
}

\section{Politicians on ice}

$\mathrm{T}$ he visit last November to King George Island by Ban Ki-Moon was the first by a UN SecretaryGeneral to Antarctica, and its organisation by Chile was definitely a political coup for the country. Landing at Chile's President Eduardo Frei Station he also visited the Uruguayan and Korean stations on the island but, interestingly, not the Russian, Chinese, Argentinean, Brazilian and Polish stations, all of which were certainly accessible from Frei. The significance of this visit in establishing the international importance of Antarctica just before the Kyoto Protocol meeting in Bali should give heart to all scientists working on the continent.

But just how important is the Antarctic politically to each of the Consultative Parties? We all know that politicians need to be seen to wave the national flag and that their public actions on particular topics are an indication of how important that subject is on their government's agenda. Science is no exception to this rule. So perhaps a possible proxy approach to assessing the importance of Antarctica is to examine the level of elected representative who has found the time to visit the continent to gain first-hand knowledge of the work.

Attempting to record all visits over the last few decades is impossible but a snapshot shows some interesting differences. Chile and Argentina have demonstrated their high level of interest with presidential visits and even a cabinet meeting at one of the Argentine stations. The Prime Minister of New Zealand recently made a visit to Scott Base, following in the footsteps of several cabinet ministers, whilst various Australian ministers and senators have also visited their stations. The UK has sent down two Ministers of State in the last 10 years, but most other European countries appear to have had no government ministers visit their stations. So what about elected representatives? The USA has a continuing effort to take Representatives and Senators down to McMurdo. The UK has done reasonably well with visits from both the House of Commons and House of Lords but who from the elected representatives of countries like Japan, Brazil, Germany, Spain, South Africa and so on has been south? And if not why not?

There have been organised attempts to get groups of government representatives down to the ice. Chile organised an international visit in 1982 at King George Island. Stimulated by the UN placing the "Question of Antarctica" on its agenda in 1983 the Beardmore Glacier workshop was organised by the USA in 1985 to bring together senior people from Antarctic science and politics with those from new countries interested in working in Antarctica. And then in 1999 there was the "Ministerial on Ice" meeting at Ross Island, convened by New Zealand and the USA as a way of drawing attention to the importance of the continent to environmental problems. For this they managed to get 42 representatives from 24 Parties to take part. Sadly, there were no representatives from Consultative Parties Belgium, Brazil, Ecuador, Spain, Ukraine, and Uruguay and many other countries were represented by only by ambassadors or senior officials rather than ministers.

Why does all this matter? For the same reason that any decisions taken by people unfamiliar with a topic are invariably improved if they have some personal experience of the field. Antarctic research is costly and is addressing problems not simply of great scientific interest but of crucial political significance, like climate change. We need politicians, as well as officials, to be personally engaged, to understand how difficult our scientific objectives are yet how important they are to everybody. More politicians visiting the continent will help everyone.

DAVID W.H. WALTON 